\title{
Ecological niche modeling of rabies in the changing Arctic of Alaska
}

\author{
Falk Huettmann ${ }^{1}$, Emily Elizabeth Magnuson ${ }^{2}$ and Karsten Hueffer ${ }^{3^{*}}$
}

\begin{abstract}
Background: Rabies is a disease of global significance including in the circumpolar Arctic. In Alaska enzootic rabies persist in northern and western coastal areas. Only sporadic cases have occurred in areas outside of the regions considered enzootic for the virus, such as the interior of the state and urbanized regions.

Results: Here we examine the distribution of diagnosed rabies cases in Alaska, explicit in space and time. We use a geographic information system (GIS), 20 environmental data layers and provide a quantitative non-parsimonious estimate of the predicted ecological niche, based on data mining, machine learning and open access data. We identify ecological correlates and possible drivers that determine the ecological niche of rabies virus in Alaska. More specifically, our models show that rabies cases are closely associated with human infrastructure, and reveal an ecological niche in remote northern wilderness areas. Furthermore a model utilizing climate modeling suggests a reduction of the current ecological niche for detection of rabies virus in Alaska, a state that is disproportionately affected by a changing climate.
\end{abstract}

Conclusions: Our results may help to better inform public health decisions in the future and guide further studies on individual drivers of rabies distribution in the Arctic.

Keywords: Rabies, Alaska, Ecologic niche, Data mining, Predictions

\section{Background}

Rabies is a global zoonotic disease that lacks satisfactory treatment and kills 50,000-70,000 people annually, mostly in developing countries where dog-associated rabies is not well controlled [1]. In developed countries rabies among wild animals poses a threat to human health through direct contact with infected wildlife or through the infection of unvaccinated dogs, and cats [2]. The economic burden of rabies is significant even in areas without large numbers of human rabies cases due to the costs of prevention efforts and required infrastructure [1].

In the circumpolar region the arctic fox (Vulpes lagopus) is considered the primary maintenance host for rabies [3]. The arctic fox has been displaced in some regions by the red fox (Vulpes vulpes) presumably driven

\footnotetext{
*Correspondence: khueffer@alaska.edu

${ }^{3}$ Department of Veterinary Medicine, University of Alaska Fairbanks, 901

Koyukuk Drive, PO Box 757750, Fairbanks, AK 99775, USA

Full list of author information is available at the end of the article
}

by anthropogenic change [4-6]. However, this trend is not found in all regions of the Arctic [7].

In Alaska, rabies is of significant concern to public health, particularly in the face of environmental change [8], see also Additional file 1 for detail on human health implications. Enzootic rabies (defined as always being present at a certain level) is believed to be primarily limited to northern and western coastal regions of Alaska that have only limited human development [9]. Occasionally epizootic rabies occurs in interior regions of Alaska [10]. Although the exact extent of enzootic regions is unknown. Large urban settlements such as the cities of Anchorage, Fairbanks and Juneau, are not directly affected by enzootic rabies apart from occasional importation of the disease through translocation of infected dogs from enzootic rural areas (for an example see [11]). The regions of Alaska with the highest burden of rabies cases in both wildlife and domestic dogs, like many other remote arctic communities, generally lack adequate veterinary care and dog vaccination. In addition, the 
true burden of rabies, especially in foxes is not known, because diagnostic testing is generally limited to incidents of possible human exposure and animals suspected of having rabies in regions considered non-enzootic. There is little active surveillance of rabies among wildlife in enzootic regions of Alaska. The majority of rabies testing occurs only in close proximity to human infrastructure. Industrial developments in remote areas are known to enhance invasive species, including diseases (see [12] for invasive species in Alaska) and can provide significant attractions to wildlife through food subsidies, as well as olfactory or light stimuli $[13,14]$.

Rabies dynamics in Alaska are characterized by cyclical increases in reported cases with 4-5 year intervals [15] (Fig. 1). During the period from 2000 to 2014, 272 animals were reported positive for rabies by the Section of Epidemiology for the State of Alaska in their annual disease reports [16-23]. Ninety-nine percent of these rabies-positive animals originated in Northern and Southwestern Alaska that are considered enzootic for wildlife rabies. In contrast South-central and parts of central interior Alaska did not contribute any cases of rabies in terrestrial mammals. The spread of arctic variant rabies into areas previously not affected poses a risk even in the more populated areas of Alaska. This can be seen by the spread of arctic variant-rabies into southern Ontario for instance [24].

Both red and arctic foxes are frequently diagnosed with rabies, but red foxes are diagnosed with rabies more often than arctic foxes [15]. Within Alaska the rabies virus is maintained as three distinct genetic variants $[25$, 26]: Arctic rabies variants 2, 3 and 4 . The general spatial distribution of these variants seems to be stable [25-27]. The biogeography and mechanism of maintaining at least three distinct strains over time is not well understood [27]. However, the population structure of arctic foxes appears to be more closely related to the distribution of rabies variants compared to the population structure of red foxes. It suggests that the mesocarnivore arctic fox is the maintenance host, while the red fox serves as a frequent spillover host for this virus. Alternatively, the red and arctic fox provide a dynamic multi-host maintenance system for arctic rabies virus variants in Alaska [27]. The consequences on rabies dynamics of a supposedly

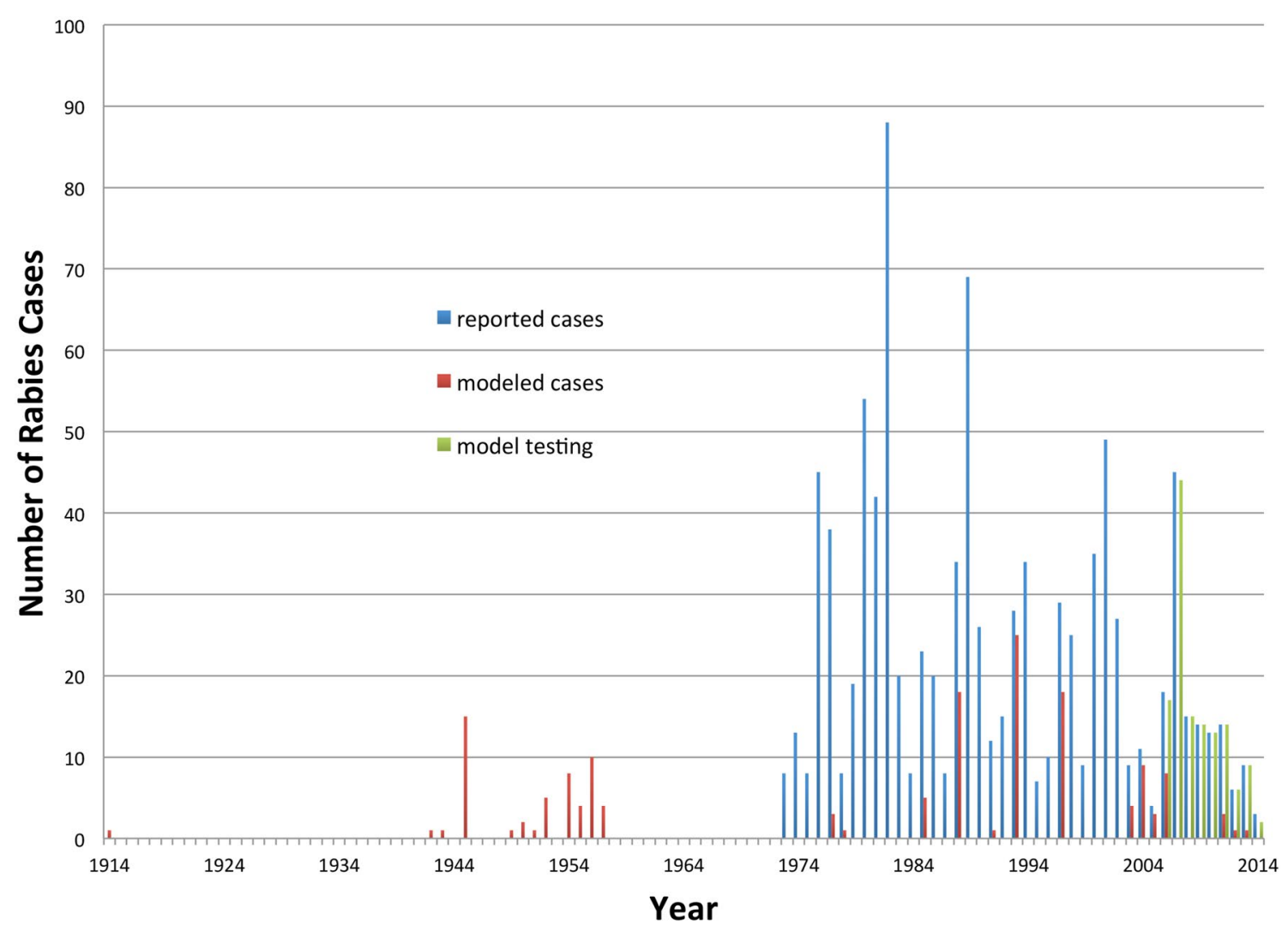

Fig. 1 Diagnosed rabies cases over time in animals and people. Blue bars represents reported cases according to the annual infectious disease reports (1973-2014) published by the Section of Epidemiology for the State of Alaska. The red bar represents cases used to train our models (Additional file 2) and the green bars represents the cases included in testing our models (Additional file 3) 
increased displacement of arctic foxes by red foxes is not known [28]. However Kutz provides examples for increased disease in Northern regions, mainly parasitic infections, associated with extreme weather events and warmer temperatures [29]. Similar dynamics could also hold true for rabies at high latitudes.

Some examples of increased disease transmission in the circumpolar North due to a changing climate have been described [30]. With climate change predicted to be more extreme at high latitudes, e.g. 10 or more degrees Celsius temperature increase during the next 100 years [31], it is imperative to base future public health decisions on the best available data and predictions [32]. This should be guided by public access, transparency, repeatability, as well as a thorough and justifiable understanding of the ecological niche occupied by the disease of concern [33].

Because of a sampling effort bias towards human development and under-sampling of animals for rabies diagnostics from remote areas, a complete picture of the presence and prevalence of rabies does not yet exist for Alaska. To overcome such problems, predictive modeling emerged as a powerful method, based on empirical data and best-available science ([34] for rabies; for other examples see [35-38]). Organisms, including pathogens and their hosts, are bound by a certain ecological niche [32, 33, 39]. Describing and predicting the ecological niche of a disease can greatly help to further our understanding of pathogen dynamics, even in the face of limited sampling [40, 41].

Following best practice and state-of-the art methods $[33,34,38,41,42]$, this investigation tried to define the quantitative envelope of the ecological niche for rabies in the Arctic using Alaska as a test case. We carried out such an analysis with an ecological niche model using machine learning algorithms, based on geographical information systems (GIS) and publicly available environmental data, applied to presence only locations of compiled rabies detections.

\section{Methods}

Publically available information on 153 diagnosed rabies cases from 1914 to 2013, in terrestrial mammals was compiled and manually divided into a stratum that occurred in areas considered enzootic by the State of Alaska Section of Epidemiology, and a second stratum diagnosed outside this enzootic area [9] (Additional file 2). The classification of enzootic or non-enzootic greatly influences rabies control measures. An independent set of recent diagnosed rabies cases (Additional file 3) was used to compare different approaches.

Rabies cases were model-predicted with machine learning algorithms comparing them to pseudo-absences (created randomly in GIS for Alaska). Classification and regression trees (CARTs)- based boosting and bagging (TreeNet, RandomForest, SPM7, Salford Systems Ltd) using the 'default' settings for those models because they are specifically designed for presence data, data mining (see Table 1 for details) were used to model the ecological niche of rabies in Alaska. These model settings generalize best for data such as used here (https://www.salfordsystems.com/products/treenet) [33, 35]. Because these models employ 'recursive partitioning' the models are

Table 1 Settings and explanations of the TreeNet model run

\begin{tabular}{|c|c|c|c|}
\hline Metric & Setting & Effect & Justification \\
\hline Learnrate & AUTO & A detailed but slow model run & $\begin{array}{l}\text { Known to provide best results for the } \\
\text { algorithm 'learning' data }\end{array}$ \\
\hline Subsample fraction & $50 \%$ & Internal testing while model is grown & $\begin{array}{l}\text { Standard approach for balanced tree } \\
\text { models }\end{array}$ \\
\hline Logistic residual trim fraction & 0.10 & Fine-tuning & Allows for better fits \\
\hline Huber-M fraction of error squared & 0.90 & Accuracy level & $\begin{array}{l}\text { A statistical standard threshold for } \\
\text { certainty }\end{array}$ \\
\hline Optimal logistic model selection & Cross entropy & How to find the optimal model & $\begin{array}{l}\text { Usually the best setting for tree-based } \\
\text { models }\end{array}$ \\
\hline Number of trees to build & 1000 & $\begin{array}{l}\text { Number of trees tried out for the best } \\
\text { solution }\end{array}$ & $\begin{array}{l}\text { This number should widely overshot } \\
\text { the known optimum }\end{array}$ \\
\hline Maximum number of nodes & 6 & $\begin{array}{l}\text { Determines the node depth of trees } \\
\text { used }\end{array}$ & $\begin{array}{l}\text { This number determines whether a } \\
\text { 'stump' or a fully fit tree is run }\end{array}$ \\
\hline $\begin{array}{l}\text { Terminal node minimum training } \\
\text { cases }\end{array}$ & 10 & $\begin{array}{l}\text { For most data cases it provides a } \\
\text { robust tree }\end{array}$ & $\begin{array}{l}\text { Number of cases for each tree branch } \\
\text { split }\end{array}$ \\
\hline $\begin{array}{l}\text { Maximum number of most-optimal } \\
\text { models to save summary results }\end{array}$ & 1 & Just 1 most-optimal model is saved & \\
\hline Regression loss criterion & Huber-M (Blend LS and LAD) & $\begin{array}{l}\text { A statistical metric to express gain vs } \\
\text { cost of a new rule }\end{array}$ & Standard approach in trees \\
\hline
\end{tabular}


rather robust for correlations and interactions, as judged by high AUC ROCs and assessment metrics [33].

The environmental layers used are shown in Table 2. These model layers are known to contribute to the ecological niche, and also act as a proxy to inquire further if deemed relevant in future studies. In addition, these layers are currently 'the best available GIS layers for the state of Alaska [35, 43, 44].

For improved inference and validity, models should be assessed for their predictive performance in order to express their reliability [33, 40]. AUC ROC inherent in Salford Predictive Modeler (SPM) was one performance metric used. Machine learning approaches, as used in this study, express the ecological niche as a relative index of occurrence (RIO) visualized in the figures along a quantitative (color) gradient, red-yellow-green. Red is essentially high RIO, yellow is a mid range value, and green is low RIO.

Finally, in order to better predict the distribution of rabies in Alaska for the future, the climate niche models of rabies was predicted to 2050, using regionalized IPPC climate models for Alaska. Predictors for this model of a possible future rabies niche are limited to climate ones because Alaska still lacks reliable and available planning scenarios for the future explicit in space and time for land cover and its socio-economic features [45, 46]. 2050 was used as a more realistic and testable 'future', and thus having a real-world application.

\section{Results}

This study provides for the first time publically available data of 153 confirmed rabies cases from 1914 to 2013 with different degrees of geo-referencing quality. This data set is available in Additional file 2 and from the authors upon request (sensu Zuckerberg [47]). This dataset is an essential part of the result. The cases of terrestrial rabies (excluding 2 bat cases) were divided into two subsets: confirmed animal rabies cases from the area of Alaska considered enzootic for rabies, and areas not considered enzootic (Fig. 2). The latter cases were considered associated with sporadic epizootics. Most of these epizootic associated cases were temporally associated with a large-scale outbreak in interior Alaska during the 1950s [10]. Using these data sets machine learning algorithms were utilized to build the following three ecological niche models each for a test which provides us the best generalization for Alaska: models were informed by (a) only cases from areas considered enzootic for rabies (enzootic cases), (b) only cases from non-enzootic areas (outbreak cases), and (c) all confirmed rabies cases. Utilizing these three approaches models were created and assessed for performance, and then predicted risk maps for rabies detection in Alaska were generated. 'Risk' is defined here as pixels with a relative index of occurrence of rabies, as predicted from the model $[35,41]$.

These maps of the relative index of occurrence varied somewhat, depending on the capability of the algorithm employed and on the data used to inform the model. However, all models predicted the northern coastal areas as high-risk areas for the detection of rabies, which is even true for models only informed by outbreak-associated samples, which excluded samples from this area. Another area consistently identified among all models is located south of the Brooks Range east of Chandalar Lake (Eastern Yukon River Basin). This area is of interest because cases from that region were not included in the data set that informed the model based on enzootic cases. However, this area was involved in the outbreak in the middle of the twentieth century [10] and it has recently seen isolated cases of rabies at its western most boundary [48].

To better compare the different approaches, the models were confronted with a compiled set of recent rabies cases detected by the Alaska State Public Health Laboratory (Fig. 3). The model based on the TreeNet algorithm and informed by all available rabies cases in our data set performed best (Fig. 4; Additional file 4). The remainder of the result section will therefore focus on this model for inference.

This TreeNet-based model identified large areas north of the Brooks Range and areas south along the coast into the Yukon Kuskokwim Delta as areas at highest risk for rabies detection in the state. Interestingly, while the Eastern Yukon River Basin was identified as a high-risk area

Table 2 Predictors of rabies in Alaska and for assembling the ecological niche

\begin{tabular}{lll}
\hline Predictor & Source & Comment \\
\hline Euclidean distance to Alaska coastline & Alaska GAP data & Obtained with ArcGIS tools \\
Euclidean distance to Alaska infrastructure & Alaska GAP data & Obtained with ArcGIS tools \\
Elevation & Alaska GAP data & \\
Monthly mean temperature & Alaska GAP data (taken from SNAP) & \\
Monthly mean precipitation & Alaska (taken from SNAP) & \\
\hline
\end{tabular}

For public data sources see $[43,44]$ 


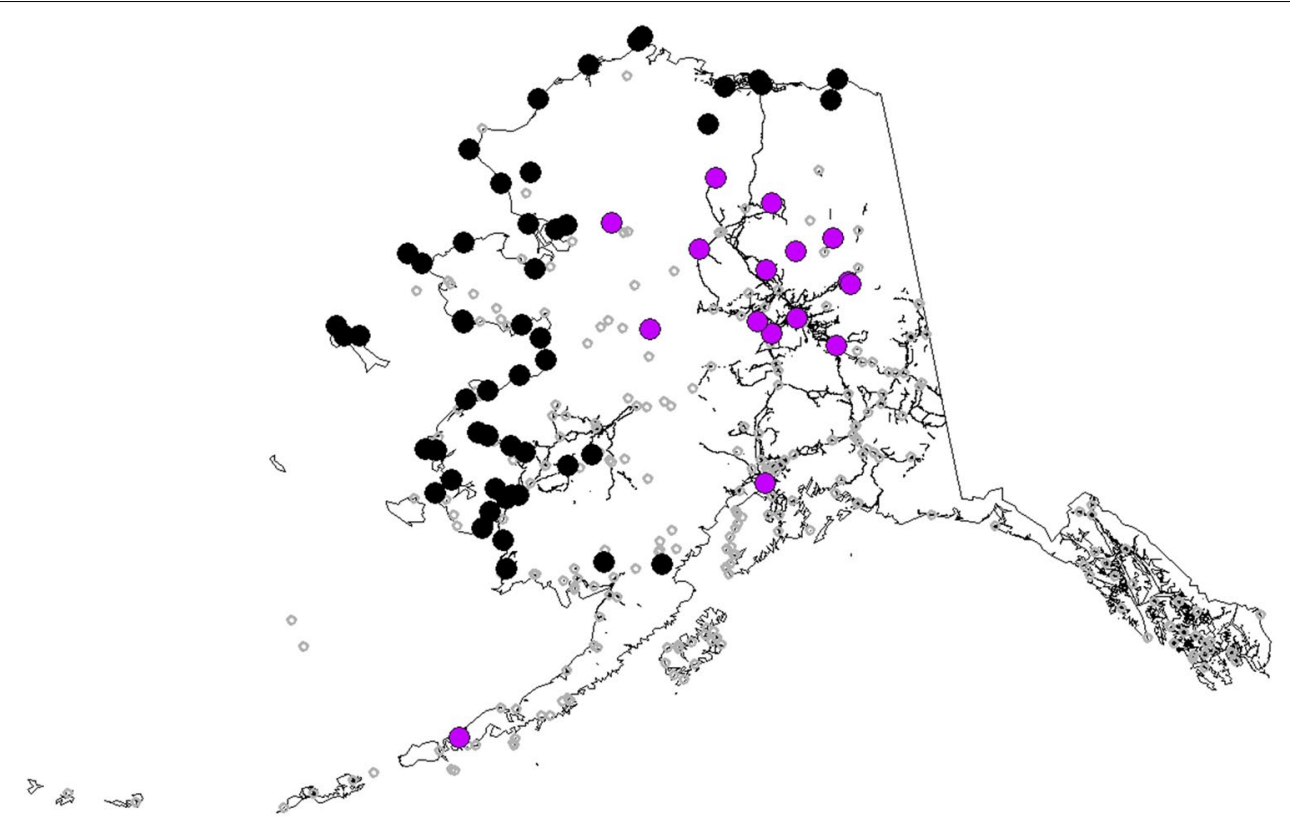

Fig. 2 Alaska map and location of diagnosed rabies cases used to build models. Cases classified as enzootic is indicated in black and epizootic cases in purple. Settlements and road infrastructure is shown in grey

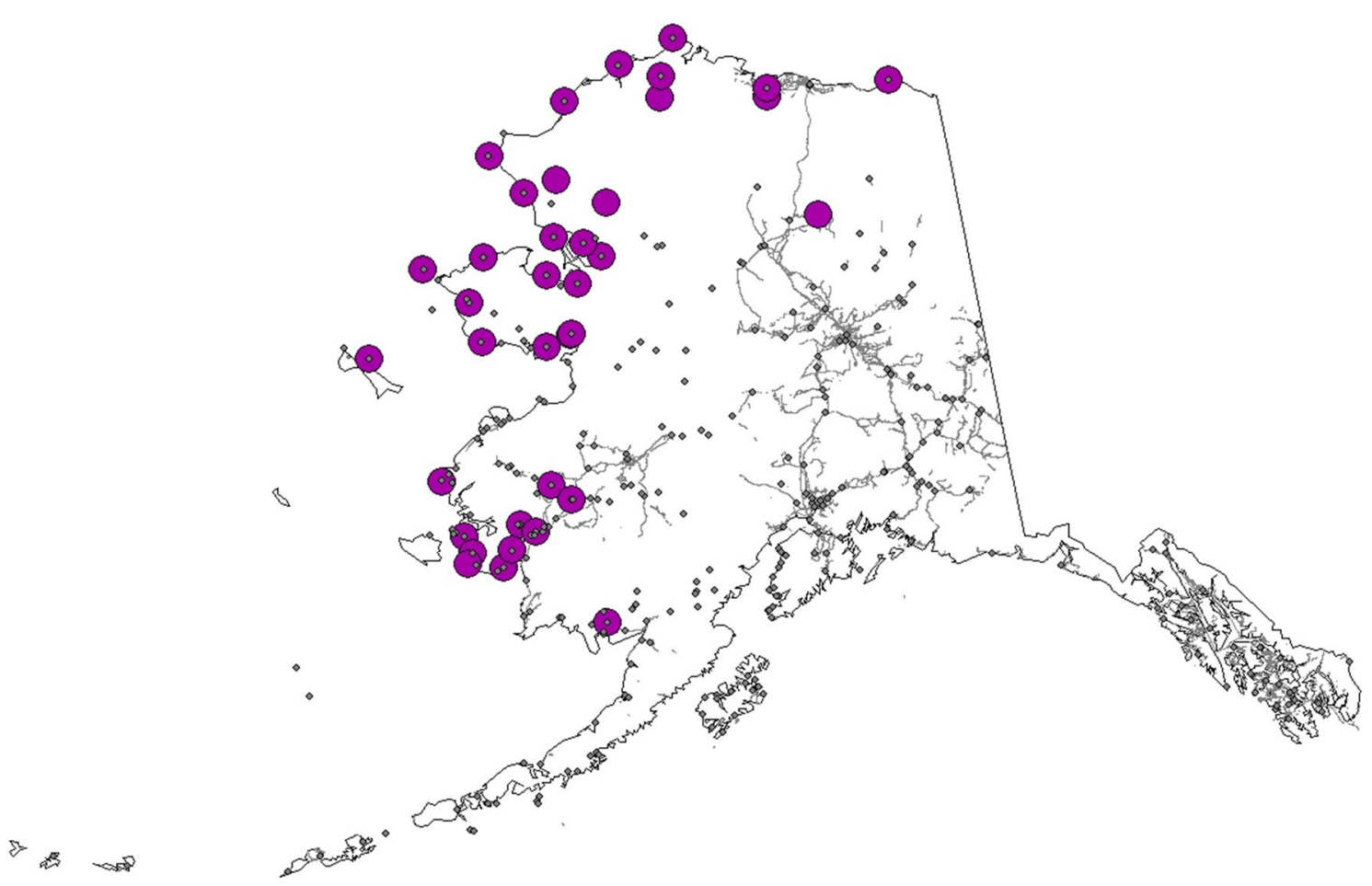

Fig. 3 Alaska map and location of diagnosed rabies cases data to assess model performance. Seventy three locations were used, representing 127 diagnosed cases to assess the models 


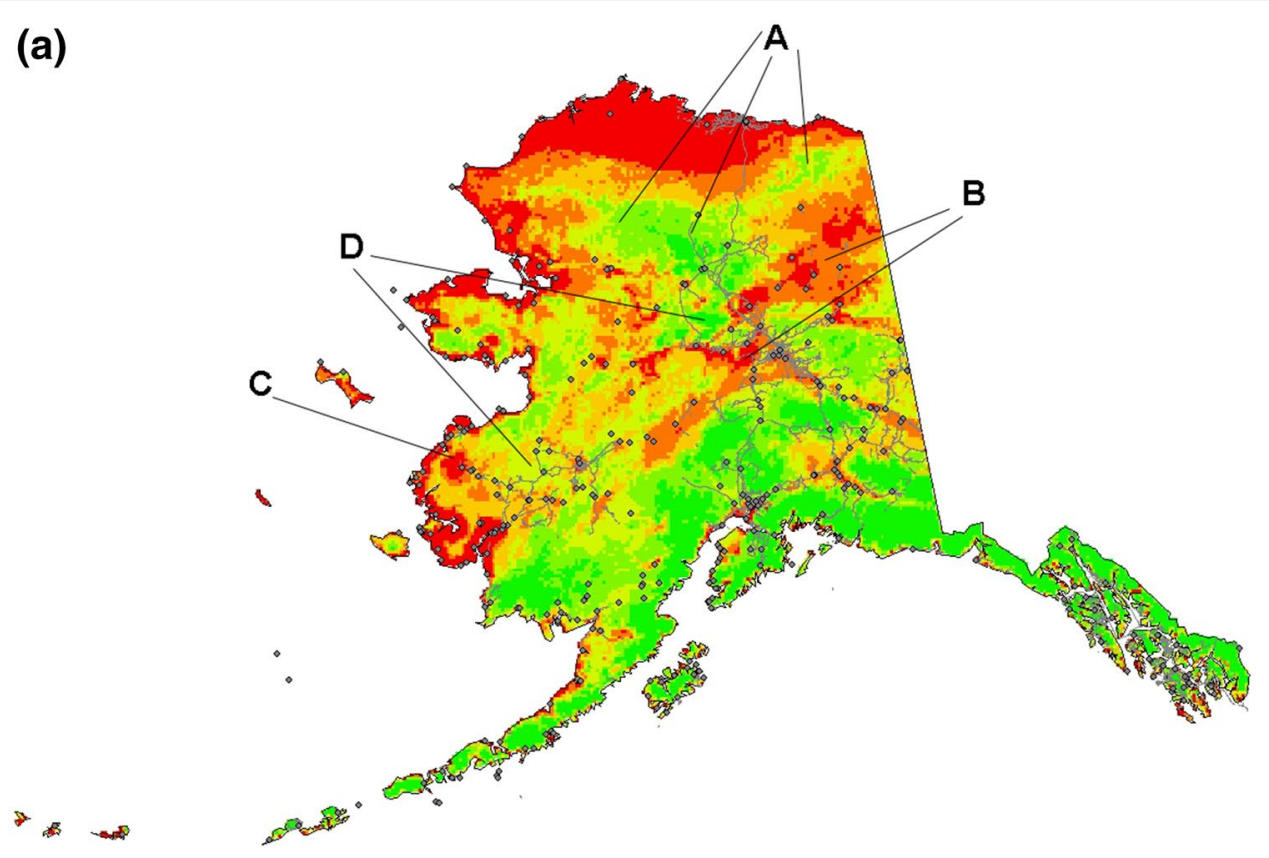

(b)

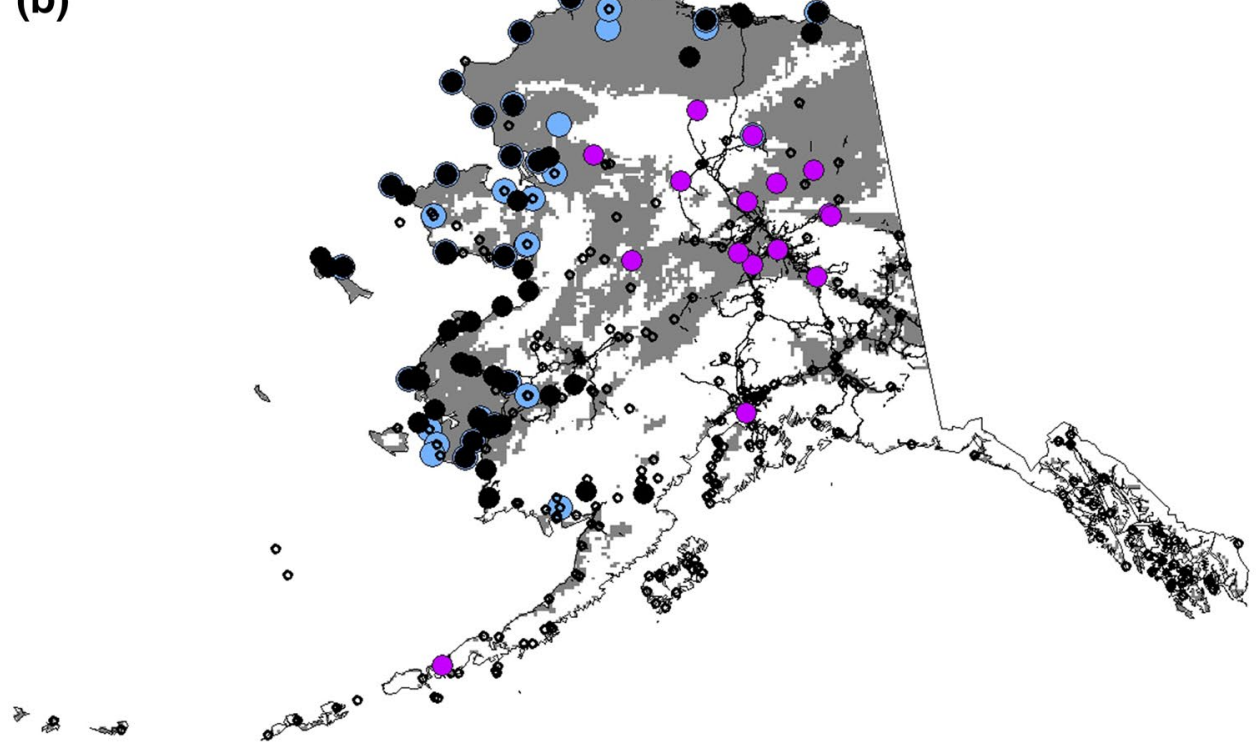

Fig. 4 a Best TreeNet model (pooled data) prediction of rabies in Alaska. Colors show relative index of occurrence (RIO), where red is high RIO, yellow is mid range RIO and green is low RIO; rabies used to build the model are overlaid for overview. Letter indicate regions of special interest in the model output: A Brooks Range, B Eastern Yukon Basin, C Lower Yukon/Yukon Delta, D Middle Yukon. b The same RIO map classified into a presence/ absence scheme. Rabies cases used to build the model are indicated in black and purple; (see Fig. 1a) and assessment data in blue) are overlaid for overview

for rabies and the mouth of that river is also identified with the high-risk area to the West, the middle section of this major river in Alaska was not identified as an area of high probability for rabies detection. Terrestrial rabies is widely predicted to be absent in southern Alaska, except for the major population center of Anchorage.
The best performing model identified distance to infrastructure, elevation, distance to coast, precipitation in June, and precipitation in February as predictors most important in defining the ecological niche (Table 3).

A model built in TreeNet using only climate variables had a lower performance than the model build on 
Table 3 TreeNet variable importance of parameters utilized in best performing model (148 Alaska rabies data locations pooled regardless of outbreak or enzootic locations)

\begin{tabular}{|c|c|}
\hline Variable & Score \\
\hline Distance to infrastructure & 100.00 \\
\hline Elevation & 56.09 \\
\hline Distance to coast & 31.95 \\
\hline Precipitation June & 30.63 \\
\hline Precipitation February & 21.78 \\
\hline Precipitation October & 20.28 \\
\hline Temperature October & 20.27 \\
\hline Precipitation March & 19.22 \\
\hline Precipitation May & 18.64 \\
\hline Temperature April & 18.49 \\
\hline Precipitation August & 18.29 \\
\hline Temperature December & 17.68 \\
\hline Temperature February & 17.56 \\
\hline Precipitation April & 16.89 \\
\hline Precipitation July & 16.77 \\
\hline Precipitation September & 16.47 \\
\hline Precipitation December & 14.99 \\
\hline Precipitation January & 13.40 \\
\hline Temperature August & 13.13 \\
\hline Temperature November & 12.93 \\
\hline Temperature January & 12.50 \\
\hline Temperature May & 11.64 \\
\hline Temperature March & 10.25 \\
\hline Precipitation November & 9.44 \\
\hline Temperature September & 8.89 \\
\hline Temperature June & 8.64 \\
\hline Temperature July & 5.62 \\
\hline
\end{tabular}

The variables are listed by importance together with their relative score in informing the model on the likelihood of rabies occurrence

all predictors (namely the human infrastructure ones). However, it repeated the general results, also identifying similar areas of the state with some extended areas in the Yukon-Kuskokwim Delta compared to a model including non-climate variables.

Unfortunately, we lack any reliable planning and forecast maps and models of infrastructure for Alaska. While those exist for many climate variables [46] they are not available for future development of human infrastructure. We therefore utilized only this climate-based ecological niche model for starting to explore the possible effects of climate change, such as warming in the Arctic and altered precipitation, on the rabies risk distribution in Alaska for the predicted climate scenario in 2050. As done elsewhere [14], we employed an ecological niche model projecting the climate-based niche onto climate data predicted for the year 2050 using the regionalized
IPCC climate model from SNAP (A1B1 scenario). This resulted in a significantly reduced area of predicted future risk of rabies detection, especially in the southern areas of current rabies risk prediction (Fig. 5).

\section{Discussion}

Disease prediction is a common effort that can increase understanding of disease ecologies, especially in remote areas [32, 35, 41, 49, 50]. Our approach to better understand rabies dynamics in the circumpolar region becomes possible due to publically available and shared data of confirmed rabies cases, as well as environmental GIS layer predictions and non-parsimonious algorithms. This modeling effort identified several geographic areas of predicted risk for rabies detection. Further, variables were identified by our modeling approach that influenced the distribution of rabies detection throughout the State, specifically the relevance of human infrastructure. A major limitation of our modeling approach was the way most of the data informing the model were collected. Rabies testing in Alaska is largely performed by the public health system with a focus, and consequent bias, towards human exposures. Vast areas in Alaska such as wilderness areas remain largely unstudied for wildlife diseases including rabies. Because of this, knowledge of rabies distribution and ecology Alaska is rather poor and biased through a human-focused detection system. The current pragmatic focus on possible human exposure could skew our model towards ignoring the true role of areas further away from human infrastructure as a variable responsible for majorly influencing the predicted presence of wildlife rabies. However, if one considers our models as an approach to determine possible risk for humans to encounter the rabies virus, this possible bias will still be very reflective of a threat to human health. On the other hand, this bias is likely leading to an underestimation of rabies cases in Alaska. It is still limiting our ability to identify additional variables influencing rabies distribution in remote areas that are relatively unaffected by human activity. Arguably, one wants to know and use as many predictors as possible to test and describe rabies outbreaks, instead of just a parsimonious one.

Our modeling approach provides predictions explicit in space and time and does not attempt to elucidate direct causal relationships between identified predictors and rabies risk. For example, the identified climate variables likely influence rabies occurrence indirectly through effects on wildlife populations rather than direct effect on virus particles or replication of the virus. However, identifying these predictors without detailed knowledge on mechanisms is still important to describe the niche and help focus public health efforts in a spatially explicit form. Large uninhabited areas of Alaska within or 


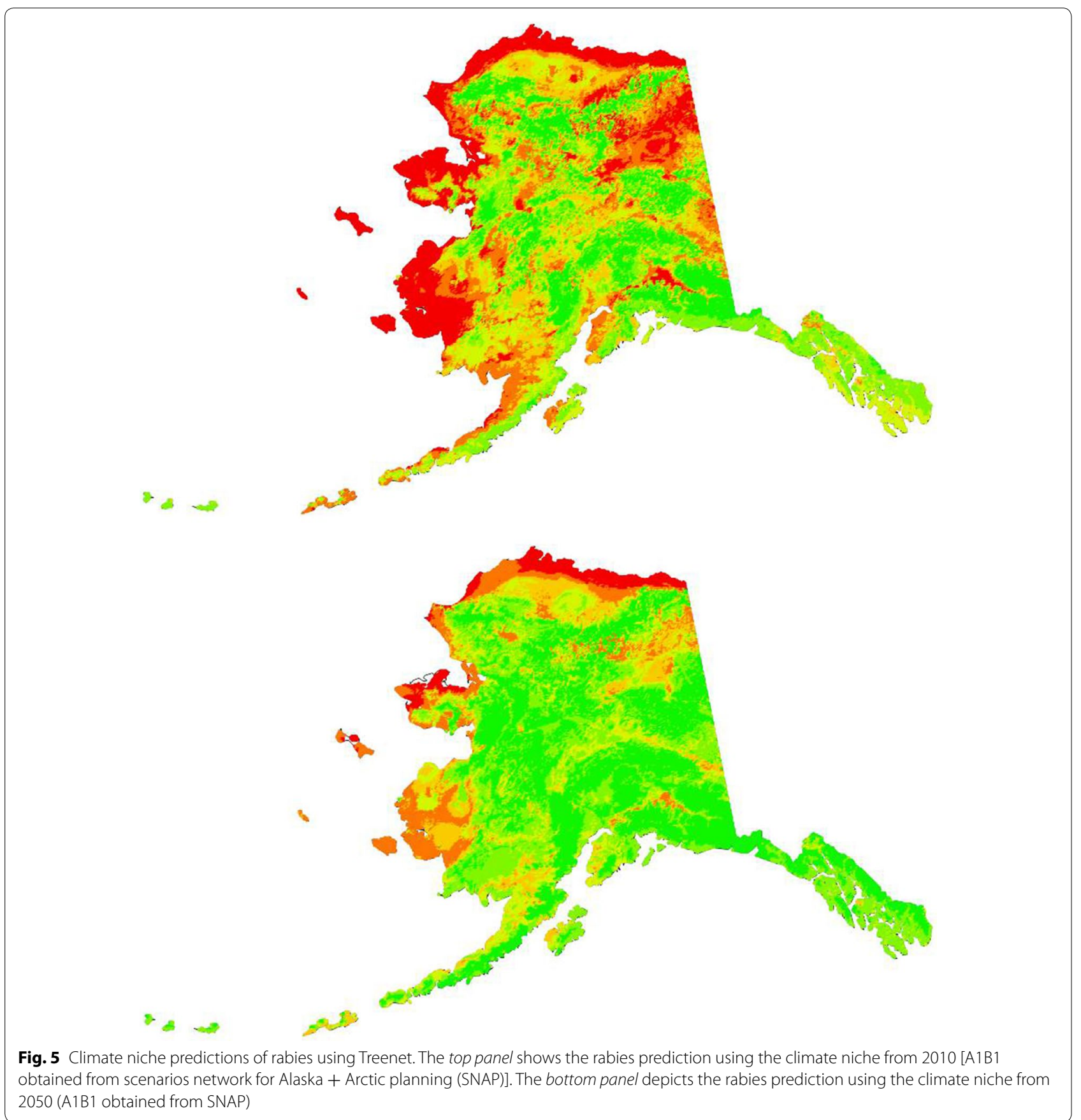

adjacent to areas considered enzootic for rabies virus are not systematically surveyed. This limits our ability to fully understand the ecological drivers of this important disease. In addition, information on possible variables at an appropriate landscape level, such as density of reservoir and spillover hosts is needed to better model the ecological drivers of rabies distribution in Alaska. An additional limitation is the possible misdiagnosis of other diseases (such as canine distemper in foxes) as rabies, especially for cases in the early stages of disease. However, as these cases follow a similar pattern to more recent cases we see this as a minor limitation only.

Our rabies forecast for the state into the future using climate models for 2050 shows a decay of the Arctic rabies niche for the arctic rabies variants. However, we currently lack any information on how rabies variants 
from the south could enter the state and how they could behave and disperse in a warming Arctic. In addition, the adaptation of the arctic rabies virus variants to a changing environment and host distribution warrants caution in overly relying on our prediction of the extent of the ecological niche for just this rabies virus variant into the future. Our finding that human infrastructure possibly plays a central role, and assuming an increase of infrastructure development, casts doubt on our prediction of reduced rabies risk in a changing Alaska.

Despite the limitations mentioned above, the modeling approach and the results presented can still help public health officials to better focus preventative efforts in the areas most at risk of rabies exposure to humans. Such efforts could include traditional measures such as possible active surveillance efforts in predicted hotspots and coldspots, increased dog vaccinations and population controls and vigilance to detect possible outbreaks or expansion of enzootic areas in the face of a changing Arctic. While currently licensed oral vaccines have been shown to be effective in protecting arctic foxes against infection with virus circulating in Alaska [51], large-scale use of these measures to control rabies are unlikely to be cost effective [51]. However, our methods, open access compilation and results might guide a more limited use of this intervention tool.

Our modeling can especially help target active surveillance efforts in less developed areas of the state. These efforts could test the model presented here and greatly advance our understanding of relevant drivers of rabies maintenance in pristine Arctic areas.

In future work this model and template should be tested and applied further with independent data, ideally data that is less biased and not dependent on human access and human exposure. We also believe that a wider macroecology view and model prediction for rabies overall, and its niche is warranted, assuming that other rabies strains from Canada or more southern regions will enter Alaska sooner or later. This pathogen transport has been seen in other disease system with influenza being a prominent example of pathogen transport to high latitudes [52]. A wider socio-economic perspective to public health and rabies across scales is required. Such an approach will clarify how the findings of our model can be extended beyond the risk of human exposure to start to explain and manage the distribution of rabies in Alaskan wildlife.

\section{Conclusions}

I this paper we showed that machine learning approaches and open data sources can help predict the ecological niche of infections disease detection for an important zoonotic disease in the Arctic. These findings can help guide future surveillance efforts as well as inform public health officials in focusing efforts on areas at high risk for rabies virus infections. Future work should test our modeled predictions and lead to further refinement of our predicted ecological niche of rabies virus in Alaska.

\section{Additional files}

Additional file 1. Public health impact of rabies in Alaska. This file contains information on the historic public heath impact of rabies in Alaska to put our findings into an appropriate context of One Health.

Additional file 2. Locations of rabies cases in Alaska 1914-2013 used in model development. This file contains the location, dates and vectors of all rabies cases used to build our models. In addition the files indicates if a case was considered part of enzootic rabies or associate with an outbreak in a non-enzootic area.

Additional file 3. Location data of rabies cases used for model assessment. This file lists the location of rabies cases provided by the Alaska Section of Epidemiology in the Department of Health and Social Services of the State of Alaska.

Additional file 4. TreeNet model summary statistics for pooled rabies locations. This file contains summary statistics for the best performing model developed in this studies. It includes partial dependence plots for the three most important predictors in the model (distance to infrastructure, Elevation, and distance to coast), genral Average likelihood statistics and a Gains chart for 104 trees.

\section{Authors' contributions}

$\mathrm{FH}$ and $\mathrm{KH}$ perceived the study. EEM and FH performed the modeling. $\mathrm{FH}$ and $\mathrm{KH}$ wrote the manuscript. All authors read and approved the final manuscript.

\section{Author details}

${ }^{1}$ EWHALE Lab, Institute of Arctic Biology, Department of Wildlife Biology, University of Alaska Fairbanks, 902 N. Koyukuk Dr., P.O. Box 757000, Fairbanks, AK 99775, USA. ${ }^{2}$ Department of Biology and Wildlife, University of Alaska Fairbanks, 982 N. Koyukuk Dr., PO Box 756100, Fairbanks, AK 99775, USA.

${ }^{3}$ Department of Veterinary Medicine, University of Alaska Fairbanks, 901 Koyukuk Drive, PO Box 757750, Fairbanks, AK 99775, USA.

\section{Acknowledgements}

Work reported in this publication was supported by the National Institute of General Medical Sciences of the National Institutes of Health under three linked awards number RL5GM118990. The work is solely the responsibility of the authors and does not necessarily represent the official view of the National Institutes of Health. R. Waltuch kindly provided the first Alaska rabies data compilation for an online UAF eLearning student project (Additional file 2). The Section of Epidemiology, State of Alaska provided data to test our models.

\section{Competing interests}

The authors declare that they have no competing interests.

\section{Availability of data and materials}

Datasets beyond those provided in the appendices, that were generated or used in the current study are available from Dr. Huettmann on reasonable request.

\section{Funding}

Work reported in this publication was supported by the National Institute of General Medical Sciences of the National Institutes of Health under three linked awards number RL5GM118990. The work is solely the responsibility of the authors and does not necessarily represent the official view of the National Institutes of Health.

Received: 16 October 2016 Accepted: 9 March 2017 
Published online: 20 March 2017

\section{References}

1. Hampson K, Coudeville L, Lembo T, Sambo M, Kieffer A, Attlan M, et al. Estimating the global burden of endemic canine rabies. PLoS Negl Trop Dis. 2015. doi:10.1371/journal.pntd.0003709.

2. Rupprecht CE, Hanlon CA, Hemachudha T. Rabies re-examined. Lancet Infect Dis. 2002;2:327-43.

3. Mørk T, Prestrud P. Arctic rabies-a review. Acta Vet Scand. 2004;45:1-9.

4. Macpherson AH. A northward range extension of the red fox in the eastern Canadian Arctic. J Mammal. 1964:45:138-40.

5. Savory G. Foxes and food subsidies: anthropogenic food use by red and Arctic foxes, and effects on Arctic fox survival, on the Arctic Coastal Plain of Alaska. M.Sc. Thesis. University of Alaska.

6. Stickney AA, Obritschkewitsch T, Burgess RM. Shifts in fox den occupancy in the greater Prudhoe Bay area, Alaska. Arctic. 2014;67:196-202.

7. Gallant D, Slough BG, Reid DG, Berteaux D. Arctic fox versus red fox in the warming Arctic: four decades of den surveys in north Yukon. Polar Biol. 2012;35:1421-31.

8. Hueffer K, Parkinson AJ, Gerlach R, Berner J. Zoonotic infections in the US Arctic (Alaska); disease prevalence, potential impact of climate change, and recommended actions for earlier disease detection, research, and prevention and control. Int J Circumpolar Health. 2013. doi:10.3402/ijch. v72i0.19562.

9. Alaska State Section of Epidemiology. http://dhss.alaska.gov/dph/Epi/id/ SiteAssets/Pages/Rabies/regions.gif. Accessed Nov 2015.

10. Rausch R. Some observations on rabies in Alaska, with special reference to wild canidae. J Wildl Manag. 1958:22:246-60.

11. Rabies in a dog brought to Anchorage from rural Alaska. In: Bulletin No. 11 2009. Alaska State Section of Epidemiology. 2009. http://epibulletins. dhss.alaska.gov/Document/Display?Documentld=223 Accessed 14 Oct 2016.

12. Alaska department of fish and game. http://www.adfg.alaska.gov/index. cfm?adfg=invasive.main. Accessed 3 Mar 2017

13. Weiser EL. Use of anthropogenic foods by glaucous gulls (Larus hyperboreus) in Northern Alaska. M.Sc. Thesis. 2010 University of Alaska Fairbanks.

14. Baltensperger AP, Mullet TC, Schmid MS, Humphries GRW, Kövér L, Huett-

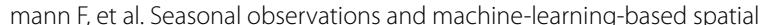
model predictions for the common raven (Corvus corax) in the urban, sub-arctic environment of Fairbanks, Alaska. Polar Biol. 2013:36:1587-99.

15. Kim B, Blanton JD, Gilbert A, Castrodale L, Hueffer K, Slate D, Rupprecht $\mathrm{CE}$, et al. A conceptual model for the impact of climate change on fox rabies in Alaska, 1980-2010. Zoonoses Public Health. 2014:61:72-80.

16. 2001 Annual (January-December) infectious disease report. In: Bulletin No. 8 2002. Alaska State Section of Epidemiology. 2002. http://epibulletins.dhss.alaska.gov/Document/Display?Documentld=318. Accessed 14 Oct 2016.

17. 2002 Annual (January-December) infectious disease report. In: Bulletin No. 5 2003. Alaska State Section of Epidemiology. 2003. http://epibulletins.dhss.alaska.gov/Document/Display?Documentld=319. Accessed 14 Oct 2016.

18. 2004 Annual (January-December) infectious disease report. In: Bulletin No. 9 2005. Alaska State Section of Epidemiology. 2005. http://epibulletins.dhss.alaska.gov/Document/Display?Documentld=321. Accessed 14 Oct 2016

19. 2006 Annual (January-December) infectious disease report. In: Bulletin No. 8 2007. Alaska State Section of Epidemiology. 2007. http://epibulletins.dhss.alaska.gov/Document/Display?Documentld=285. Accessed 14 Oct 2016

20. 2008 Annual (January-December) infectious disease report. In: Bulletin No.14 2009. Alaska State Section of Epidemiology. 2009. http://epibulletins.dhss.alaska.gov/Document/Display?Documentld=220. Accessed 14 Oct 2016.

21. 2010 Annual (January-December) Infectious Disease Report. In: Bulletin No. 7 2011. Alaska State Section of Epidemiology. 2011. http://epibulletins.dhss.alaska.gov/Document/Display?Documentld=156. Accessed 14 Oct 2016
22. 2012 Annual (January-December) infectious disease report. In: Bulletin No. 14 2013. Alaska State Section of Epidemiology. 2013. http://epibulletins.dhss.alaska.gov/Document/Display?Documentld=92. Accessed 14 Oct 2016.

23. 2014 Annual (January-December) infectious disease report. In: Bulletin No. 12 2015. Alaska State Section of Epidemiology. 2015. http://epibulletins.dhss.alaska.gov/Document/Display?Documentld=36. Accessed 14 Oct 2016.

24. Nadin-Davis SA, Muldoon F, Wandeler Al. Persistence of genetic variants of the arctic fox strain of Rabies virus in southern Ontario. Can J Vet Res. 2006;70:11-9.

25. Kuzmin LV, Hughes GJ, Botvinkin AD, Gribencha SG, Rupprecht CE. Arctic and Arctic-like rabies viruses: distribution, phylogeny and evolutionary history. Epidemiol Infect. 2008;136:509-19.

26. Nadin-Davis SA, Sheen M, Wandeler Al. Recent emergence of the Arctic rabies virus lineage. Virus Res. 2012. doi:10.1016/j.virusres.2011.10.026

27. Goldsmith EW, Renshaw B, Clement CJ, Himschoot EA, Hundertmark $\mathrm{KJ}$, Hueffer $\mathrm{K}$, et al. Population structure of two rabies hosts relative to the known distribution of rabies virus variants in Alaska. Mol Ecol. 2016:25:675-88.

28. Hueffer K, O'Hara TM, Follmann EH. Adaptation of mammalian hostpathogen interactions in a changing Arctic environment. Acta Vet Scand. 2011. doi:10.1186/1751-0147-53-17

29. Kutz S. Polar diseases and parasites: a conservation paradigm shift. In: Huettmann F, editor. Protection of the three poles. Tokyo: Springer; 2012. p. 247-64.

30. Kutz SJ, Hoberg EP, Polley L, Jenkins EJ. Global warming is changing the dynamics of Arctic host-parasite systems. Proc R Soc B Biol Sci. 2005:272:2571-6.

31. Meltofte $H$, Christensen TR, Elberling B, Forchhammer MC, Rasch M. HighArctic ecosystem dynamics in a changing climate: ten years of monitoring and research at Zackenberg Research Station, Northeast Greenland. Adv Ecol Res. 2008:40:223-48.

32. Peterson AT, Soberon J, Pearson RG, Anderson RP, Martinez-Meyer E, Nakamura M, et al. Ecological niches and geographic distributions. New Jersey: Princeton University Press; 2011.

33. Drew CA, Wiersma Y, Huettmann F. Predictive species and habitat modeling in landscape ecology. New York: Springer; 2011.

34. Escobar LE, Peterson AT, Papes M, Vogel GM. Ecological approaches in veterinary epidemiology: mapping the risk of bat-borne rabies using vegetation indices and night-time light satellite imagery. Vet Res. 2015. doi:10.1186/s13567-015-0235-7.

35. Herrick KA, Huettmann F, Lindgren MA. A global model of avian influenza prediction in wild birds: the importance of northern regions. Vet Res. 2013. doi:10.1186/1297-9716-44-42

36. Gomez-Palacio A, Arboleda S, Dumonteil E, Peterson AT. Ecological niche and geographic distribution of the Chagas disease vector, Triatoma dimidiate (Reduviidae: Triatmoniae): evidence for niche differentiation among cryptic species. Infect Genet Evol. 2015. doi:10.1016/j. meegid.2015.08.035.

37. Koch LK, Cunze S, Werblow A, Kochmann J, Doerge DD, Mehlhorn H, Klimpel S. Modeling the habitat suitability for the arbovirus vector Aedes albopictus (Diptera: Culicidae) in Germany. Parasitol Res. 2015. doi:10.1007/s00436-015-4822-3

38. Escobar LE, Qiao H, Peterson AT. Forecasting Chikungunya spread in the Americas via data-driven, empirical approaches. Parasite Vector. 2016. doi:10.1186/s13071-016-1403-y.

39. Cushman S, Huettmann F. Spatial complexity, informatics and wildlife conservation. Tokyo: Springer; 2010.

40. Breiman L. Statistical modeling: the two cultures. Stat Sci. 2001;16:199-231.

41. Peterson AT. Mapping disease transmission risk: enriching models using biology and ecology. Baltimore: Johns Hopkins University Press; 2014.

42. Williams B, Rogers D, Staton G, Ripley B, Booth T. Statistical modelling of georeferenced data: mapping tsetse distributions in Zimbabwe using climate and vegetation data. In: Perry BD, Handsen JW, editors. Modelling vector-borne and other parasitic diseases. Nairobi: ILRAD; 1992. p. 267-80

43. Baltensperger AP, Huettmann F. Predicted shifts in small mammal distributions and biodiversity in the altered future environment of Alaska: an open access data and machine learning. PLoS ONE. 2015. doi:10.1371/ journal.pone.0132054. 
44. Ohse B, Huettmann F, Ickert-Bond S, Juday G. Modeling the distribution of white spruce (Picea glauca) for Alaska with high accuracy: an open access role-model for predicting tree species in last remaining wilderness areas. Polar Biol. 2009;32:1717-24.

45. Huettmann F, Franklin SE, Stenhouse GB. Predictive spatial modeling of landscape change in the Foothills Model Forest. For Chron. 2005;8:525-37.

46. Scenarios network for Alaska and Arctic planning SNAP https://www. snap.uaf.edu/. Accessed 3 Mar 2017.

47. Zuckerberg B, Huettmann F, Friar J. Proper data management as a scientific foundation for reliable species distribution modeling. In: Drew CA, Wiersma Y, Huettmann F, editors. Predictive species and habitat modeling in landscape ecology. New York: Springer; 2011. p. 45-70.

48. Second wolf from Chandalar Lake tests positive for rabies. In: Press release May 2 2013. Alaska Department of Fish and Game. 2013. http:// www.adfg.alaska.gov/index.cfm?adfg=pressreleases.pr05022013_wolf. Accessed 14 Oct 2016.

49. Caminade C, Kovats S, Rocklov J, Tompkins AM, Morse AP, Colon-Gonzales FJ, et al. Impact of climate change on global malaria distribution. Proc Natl Acad Sci USA. 2014;111:3286-91.

50. Reeves T, Samy AM, Peterson AT. MERS-CoV geography and ecology in the Middle East: analyses of reported camel exposures and a preliminary risk map. BMC Res Notes. 2015. doi:10.1186/s13104-015-1789-1.

51. Follmann EH, Ritter D, Swor R, Hueffer K. Preliminary evaluation of Raboral $\mathrm{V}-\mathrm{RG}^{\circledR}$ oral rabies vaccine in Arctic foxes (Vulpes lagopus). J Wildl Dis. 2011:47:1032-5.

52. Winker K, McCracken KG, Gibson DD, Pruett CL, Meier R, Huettmann F, et al. Movements of birds and avian influenza from Asia into Alaska. Emerg Infect Dis. 2007;13:547-52.

\section{Submit your next manuscript to BioMed Central and we will help you at every step:}

- We accept pre-submission inquiries

- Our selector tool helps you to find the most relevant journal

- We provide round the clock customer support

- Convenient online submission

- Thorough peer review

- Inclusion in PubMed and all major indexing services

- Maximum visibility for your research

Submit your manuscript at www.biomedcentral com/submit 